\title{
Review of After-Sales Service Concepts
}

\author{
Asbjørn Rolstadaas ${ }^{1}$, Hans-Henrik Hvolby ${ }^{2}$, Peter Falster ${ }^{3}$ \\ 1) Department of Production and Quality Engineering, \\ University of Science and Technology, Norway \\ 2) Department of Production, Aalborg University, Denmark \\ 3) Department of Informatics and Mathematical Modelling, \\ Technical University of Denmark
}

\begin{abstract}
For many manufacturing companies, after-sales service is an increasingly important part of the business and is more complex than manufacturing products. Unlike products it is not possible to produce services in advance and inventory these for future consumption. Instead an unpredictable event such as a machine failure triggers a need for manufacturing of parts for replacement and allocation of resources for the service. Various aspects of after-services are discussed with regards to business model, methodology, performance metrics, service portfolio and production planning and control.
\end{abstract}

\section{Introduction}

After-sales service processes play an integral role in many companies. Even though these processes are not the core business of engineering companies, services are increasing in importance. As products in the global market become more and more similar, supply chain management and services are becoming key differentiators between companies. High-quality service has become a necessity to retain customers for future sales.

Aftermarket business also represents significant revenue and growth potential for capital goods manufacturers. Against this background Accenture launched the "Aftermarket Monitor 2005" analysing the aftermarket capabilities of 58 leading capital goods manufacturers in the Nordics: "Nordic capital goods manufacturers do not fully use their aftermarket business as a strategically important source of revenue and profitability. Only $22 \%$ of companies surveyed generate $>30 \%$ of their revenue in the service \& parts sector; and $36 \%$ of the companies have experienced $>10 \%$ growth in their after sales and service business over the last 3 years". In the AMR Research report - august 2002 it is said that services represent $25 \%$ of revenue and contribute $45 \%$ of profits.

Please use the following format when citing this chapter:

Rolstadaas, A., Hvolby, H.-H. and Falster, P., 2008, in IFIP International Federation for Information Processing, Volume 257, Lean Business Systems and Beyond, Tomasz Koch, ed.; (Boston: Springer), pp. 383-391. 
According to the Promise project [1] the life cycle of a product is characterised by the following three phases:

- Beginning of Life (BOL), including Design and Production,

- Middle-of-Life (MOL), including Use, Service and Maintenance and

- End-of-Life (EOL), characterised by various scenarios such as: reuse of the product with refurbishing, reuse of components with disassembly and refurbishing, material reclamation without disassembly, material reclamation with disassembly and, finally, disposal with or without incineration.

This also relates after-sales services closely to the definition of e-business: "planning and execution of front-end and back-end operations in a supply chain using the Internet. The Internet redefines how operations, like product design, production, after-sales service, etc. are conducted" [4].

The focus in this paper is on Middle-of-Life, i.e. the Service and Maintenance phase. Thus, the purpose of this paper is to discuss after-sales service processes and its relationships to the total life-cycle of a product in general, and business models, methodologies, service portfolio, performance metrics and production planning and control in particular.

\section{After-sales service in the supply chain}

Demands for repairs and spare parts appear unexpectedly and sporadically and after-sales networks therefore operate in an unpredictable and inconsistent marketplace. The service supply chains are more complex than the manufacturing supply chain as can be seen in figure 1 .
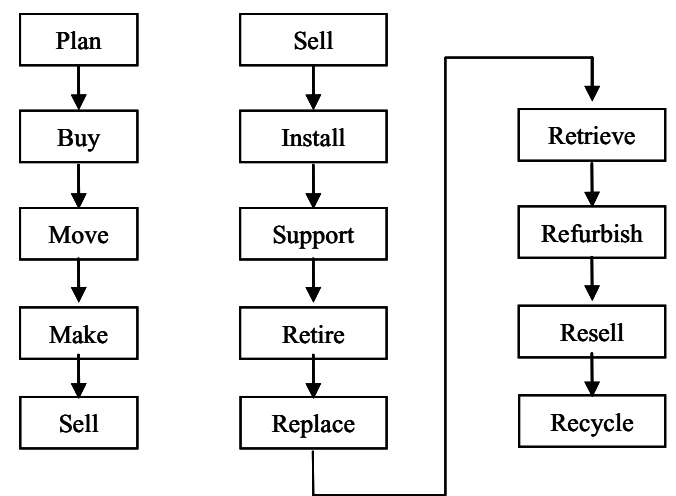

Fig. 1. Manufacturing Supply Chain (left) and Service Supply Chain (right) [6].

Wise and Baumgartner [5] document that the installed-base-to-new-unit ratio for automobiles is of 13 to 1 . Furthermore, based on stagnant product demand a push downstream is seen and also a shift from manufacturing towards providing services 
to operate and maintain products. In other words, product sale is just a way for the provision of future services.

Wise and Baumgartner further set up nine metrics in order to provide useful insight into 1) the attractiveness of the downstream business, 2) the importance of forging strong customer relationships, and 3) the power of the distribution channel. They state that "the old metrics (market share, cycle time, and quality levels) tend to focus solely on the product. Managing downstream businesses requires looking at new variables such as profit per installed unit, share of customer's total downstreamactivity spending, and total customer return over the product life cycle".

With after-markets becoming four to five times larger than the original equipment businesses Cohen et al. [7] also stress the importance of offering solutions instead of products, i.e. selling spare parts and after-sales services- conducting repairs; installing upgrades; reconditioning equipment; carrying out inspections and day-to-day maintenance; offering technical support, consulting, and training; and arranging finances - for future profits and revenues.

Especially in after-sales support of one-of-a-kind products, manufacturers are not able to store spare parts for each sold component. This often results in poor service for the customers when breakdown occur unexpectedly [7]. Basically, the problem with the market of after-sales service is their reactionary nature. This is why aftersales service must be more involved in preventative maintenance scheduling for customers.

McKinsey [8] points at that putting a price on services is more difficult than pricing products, because the benefits of services are less tangible and they often lack well-documented standard unit-production costs as a benchmark. Service costs can vary significantly by configuration, accessibility, and age of equipment, usage patterns, operating conditions, region and even individual technicians.

According to Kiritsis [1] the development of Product Embedded Information Devices (e.g. Radio Frequency Identification products) is expected to progress rapidly within advanced Product Lifecycle Management and real-time datamonitoring throughout the Product Supply Chain and explode into a multi-billion dollar market in 2006 and beyond. This technology will particularly allow producers of mass customised products to easily identify the product and its previous maintenance records and thereby improve their service.

\section{Service Networks}

Wise and Baumgartner [5] quotes Gartner Group for founding that a buyer of a locomotive engine ends up spending 21 times its purchase value to support its use. And Allmendinger and Lombreglia [10] suggest that any asset that costs more than 10 times its purchase value to use is clear candidate for networking.

Hartel \& Burger [9] state that SMEs find it difficult to maintain their own worldwide service networks at reasonable costs and argue that companies have to build service cooperation. Therefore, they propose a reference model including a guideline to form inter-enterprise service collaboration, so-called service virtual enterprise. 
A virtual enterprise can briefly be characterized as a short-term inter-enterprise cooperation where individual enterprises join core competencies in order to establish a value chain configured exactly to meet a specific customer demand. They see a service virtual enterprise consisting of three entities: 1) The service network of all potential network members, 2) the Service Virtual Enterprise (SVE) of selected member, and 3) the services as a product offered by the SVEs. The structural arrangement of these entities has been captured in the Virtual Enterprise Reference Architecture (VERA) and based on the GERAM architecture.

With focus on one-of-a-kind industry Kauer [3] defines a SVE as "a short-term form of cooperation to fulfil services among legally independent one-of-a-kind producers, service companies, suppliers or sub-contractors in a service network of long-term duration".

Allmendinger and Lombreglia state that it is not enough to offer services; it will have to provide smart services. To provide they must build intelligence into the products themselves. As they state: "smart services are based upon actual evidence that a machine is about to fail, that a customer's supply of consumables is about to be depleted, and so on". As an example they mention Heidelberg's printing machines. With machine communication over the Internet, relaying information about their status between the print shops and Heidelberg's regional and global technical support specialists, the company has the access and insight to optimise printing performance in customers' shops. The keyword is networking and connected products. Connected products will be able to perform the following functions: status, diagnostics, upgrades, control and automation, profiling and behaviour tracking, replenishment and commerce, location mapping and logistics.

\section{Planning Processes and Managing Service Networks}

In order to break a planning process into more manageable parts Franksen proposes in [19] to break the planning process into two generic steps: 1) Design of a technique (re-engineering) and 2) Operation of a technique.

The first step is one of synthesis in which we specify a system configuration by stating its structural properties. This step describes uniquely the inter-relationships between resources and products. Design of a technique is an open-ended problem in which we establish, heuristically, a production system in terms of its causal logicphysical and temporal relationships. The second step is one of analysis in which we investigate a specified system configuration in order to operate it most efficiently or economically. This decomposition is also in agreement with the concept of timehorizons in economic theory and production planning. Operation of a technique is a short-run situation where it is only possible to increase/decrease the services of certain resources such as purchase of raw material. Design of a technique is a longrun situation where it is possible to vary the structure of the production method by substitution of system configurations implying time-consuming processes. Thus, all resources and technical coefficients can be made variable.

Let's relate these generic steps with Cohen et al. [7] who say that given the complexity involved in managing service assets, companies should break the 
decision-making process into three planning periods. At the most immediate level of planning (days), companies should worry about repositioning decisions such as replenishment, allocation, and transhipment of resources. At the next level (weeks or months), managers should address the strategic positioning of material, human, and knowledge resources. At the furthest level of planning (years), companies must make decisions about the services strategy. The two top levels of Cohen et al. correspond to our long run situation.

In order to monitor performance Cohen et al. further suggest two kinds of metrics to prove useful: customer-focused and internally focused. Customer-focused metrics such as the waiting time for technical assistance, the waiting time for diagnosis, and the waiting time for the delivery of parts can help determine how efficiently a company creates value for its customers. Internally focused metrics such as fill rates and parts obsolescence costs can quantify the way companies use their service assets. In a more generalized set-up Cohen et al. [7] propose six steps for managing service networks:

1. Identify which products to cover. Support all, some, complementary, or competing products.

2. Create a portfolio of service products. Position service products according to response times and prices.

3. Select business models to support service products. Use different models for different products and life cycle stages.

4. Modify after-sales organizational structures. Provide visibility, incentives, and focus for services.

5. Design and manage an after-sales services supply chain. Decide location of resources, prioritise resource utilization, and plan for contingencies

6. Monitor performance continuously. Evaluate against benchmarks and customer feedback.

\section{Portfolio of service products}

Searching the internet illustrates quite well the companies' portfolio of after-sales services. The following sites have been studied: Nilfisk Advance [11], Niro [12], Siemens [13], ABB [14] and Heidelberg [15].

Siemens' after sales services program SIMAIN has been developed to meet the special needs of makers and marketers of electrical components, equipment, and systems as well as the requirements of machine tool makers and plant engineering companies. They provide a series of service modules: Field-and On-line Service performed directly at customer's site or via online connection (On-site Fault Elimination, Remote Monitoring, Management of Call desks and Helpdesks, On-call Service, Reliability Solutions), Repair Service is services that are performed in Siemens service centres (Repair, Calibration), Logistics Service is services to support and/or optimise customers service processes (Integration of logistics management systems, Management of returns, Spare parts management, Supply of instruments and tools), Service packages comprise service modules that are selected and 
combined according to individual requirements, technical synergy effects, or specific industrial processes.

ABB service guide provides a full range of lifecycle services from spare parts and equipment repair, training, migration to remote monitoring and technical support. Their services are the following: Performance and System Services (Asset Assessment, Consulting, Optimisation, Performance Services), Support and Maintenance Services (Installation \& Commissioning, Maintenance \& Field Services, Spare Parts \& Repair, Support \& Remote Services), Retrofit and Modernization (Environmental, Migration \& Retrofits) and Training.

Synthesising the sites it turns out that companies offer the following categories of services as Kauer et al [3] have shown:

1 General support (basic means of communication)

2 Self support (by information available by the producer)

3 Remote support (ICT- supported interaction

4 On-site support (producer or service partner present)

Kauer et al relate the services to the phases pre-sales, sales, and after-sales as illustrated in the Service portfolio table below.

\begin{tabular}{|c|c|c|c|}
\hline Services & Pre-sales & Sales & After-sales \\
\hline \multirow[t]{3}{*}{ 1. General support } & \multicolumn{3}{|c|}{ Helpdesk, contact, hotline } \\
\hline & & \multicolumn{2}{|c|}{ Training, upgrades } \\
\hline & & \multicolumn{2}{|c|}{ Spare part management } \\
\hline \multirow[t]{3}{*}{ 2. Self support } & \multicolumn{3}{|c|}{ Product information, product news } \\
\hline & \multicolumn{3}{|c|}{ Software download } \\
\hline & & \multicolumn{2}{|c|}{ Troubleshooting database } \\
\hline \multirow[t]{4}{*}{ 3. Remote support } & \multicolumn{3}{|c|}{ Remote consulting } \\
\hline & & \multicolumn{2}{|c|}{ Remote optimisation } \\
\hline & & & Remote diagnostic \\
\hline & & & Remote control \\
\hline \multirow[t]{4}{*}{ 4. On-site support } & & \multicolumn{2}{|c|}{ Process support, optimisation } \\
\hline & & \multicolumn{2}{|c|}{ Optimisation } \\
\hline & & & Maintenance \\
\hline & & & Repair \\
\hline
\end{tabular}

Hvam et al $[16,17]$ describe new ways of using configuration systems for the targeting field services, technical support and after sales. They argue that because of lack of updates in the Customer Relationship Management system, the salesman or service technician use considerable resources to figure out the status of the product. Modularised products will change throughout their lifetime, as it is possible to change the set-up, extend the product, and exchange defective parts. Product service systems are proposed as an alternative business model in the future. Their idea is to integrate a configuration system with the product - embedded configuration - and 
thereby give customers a decision support system for daily maintenance of the product. Furthermore, they visualize that service contracts are configured as other products using for example a commercial tool like Array Configuration [18].

\section{Business Models and Production Control}

Various definitions of business models exist. According to Rappa [20] a business model is the method of doing business by which a company can sustain itself - that is, generate revenue. The business model spells-out how a company makes money by specifying where it is positioned in the value chain.

Service supply chains are described by the following characteristics: Business model seen either from the manufacture's point of view or the customer's point of view.

A business model from the customer's point of view is dependent on the service priority ranging from none to very high and who is the owner of the product (manufacturer or customer). The business models are then of the types: Disposal, Ad hoc, Warranty, Lease, Cost-plus, Performance-based and Power by the hour [7].

Business models seen from the manufacturer's point of view could be of the type as described by Allmendinger and Lombreglia [10]. They propose four business models, briefly summarized below:

1 The embedded innovator which is the most products centric of the models.

2 The solutionist who considers the single product as the dominant gateway to a business opportunity, but the scope of high-value activities associated with the product is broader.

3 The aggregator who connects several disparate devices within an environment to create a high-value body of data, as a single device or a single vendor of itself may not be valuable enough to create an opportunity.

4 The synergist who provides intelligent devices that play well with others and thereby contribute valuable data or functionality to other connected products.

Looking at the business opportunities available for a company, there are two possibilities: It may be that most of the elements of the opportunity are attached directly to the product's life cycle, so the company will be able to pursue the opportunity alone. Or it may be that the opportunity lies mainly in the adjacent activities related to their product's primary activities, so that they will have to partner with others, cf. the business models. This is left for further study.

The interplay between production control and the business model should also be considered. Choice of business model should influence the choice of control concepts depending of production form (volume/variety), industry sector (uncertainty/complexity), type of product structure (convergent/divergent) and market interaction strategies. 


\section{Conclusion}

The paper has discussed concepts for after-sales service processes. The paradigm in service management today is shifting from Customer Relationship Management to Customer Managed Relationships for example by providing a customer visibility into the stock levels of various spares; the manufacturers can enable customers to manage their spares inventory better. Further aspects to be considered are described in the following.

Many manufacturing industries have been based on a horizontal integration of the value chain controlling suppliers and distributors. Both because of huge investment and difficulty in planning and control, a shift from vertical to horizontal integration of value chains has been seen. However, with networking and new ICT tools and architectures like Service Oriented Architectures (SOA) and Business Process Management, supply chains move to what has been called Virtual Vertical Integration. The impact of this shift on after-sales services is important to consider in the future. SOA provides a framework and architecture for interconnecting applications and software components seamlessly. This provides for more flexible loose coupling of resources than in traditional systems architectures. This is foreseen as important for effective managing the after-sales service supply chain.

It has been common practice to consider the enterprise as being hierarchical in both structure and control. However, a distributed view where organisational units communicate over intra- and internet and cooperate in both problem solving and action has evolved. A need for processes or agents to communicate directly with each other is emerging. This tendency is seen within production. A decentralized operation system for after-sales services can be built by local 'intelligent' agents who perform well defined tasks coordinated by the central control. In case of operational disturbance you should be able to detect the faults and to reduce the extent of the damage while being able to re-establish normal operation within very short time.

\section{References}

1. Kiritsis, D; Ubiquitous Product Lifecycle Management using Product Embedded Information Devices, IMS 2004.

2. Moseng, Bjørn; Promise project description, www.promise.no, Sintef Technology and Society, 2006.

3. Kauer, Martin; Burger, $G$ and Hartel, Ingo; An Internet-based Platform for Distributed After-sales Services in the One-of-a-kind Production, in Global Engineering and Manufacturing in Enterprise Networks, Globeman (I. Karvonen et al), Vtt symposium 224, Helsinki, 9.-10.12.2002, 2003.

4. Lee, H. L and Whang, S; E-business and supply chain integration, Sgscmf-W22001, Nov. 2001.

5. Wise, Richard and Baumgartner, Peter; Go Downstrem - The new profit imperative in manufacturing, Harvard Business Review, 133-141, SeptemberOctober 1999. 
6. Customer Annuity - successful companies will make customer service and aftersales support their competitive advantage, Ups, 2005.

7. Cohen, Morris A; Agrawal, Narendra and Agrawal, Vipul; Winning in the Aftermarket (HBR OnPoint Enhanced Edition), Harward Business Review OnPoint Article, May, 2006.

8. Bundschuh, R.G and Dezvane, T. M; How to make after-sales services pay off, The McKinsey Quarterly, 4, 2003.

9. Hartel, Ingo; Burger, Gerhard; Kamio, Y and Zhou, M; A Reference Model for Collaborative Service, in Global Engineering and Manufacturing in Enterprise Networks, Globeman (I. Karvonen et al), Vtt symposium 224, Helsinki, 9, 2003.

10. Allmendinger, Glen and Lombreglia, Ralph; Four Strategies for the Age of Smart Services, Harvard Business Review, 131-145, Oct. 2005.

11. Nilfisk website, www.nilfisk-advance.com/Info/AfterSalesService.aspx, last accessed 21 Jan. 2007.

12. Niro website, www.niroinc.com/html/after_sales/spare.html, last accessed 21 Jan. 2007.

13. Siemens website, www.industry.siemens.com/siemensindustrialservices/en/ solution_services/olm-ass/after-sales-service.htm, last accessed 21 Jan. 2007.

14. ABB website, www.abb.us/ServiceGuide last accessed 21 Jan. 2007.

15. Heidelberg website, www.heidelberg.com/www/html/en/content/overview1/ service/service_support_overview, last accessed 21 Jan. 2007

16. Teglgaard Christensen, Tim and Hvam, Lars; A configuration System for supportive Purposes in the middle of a product lifecycle. in "Customer Interaction and Customer Integration Series on Business Informatics and Application Systems", 2, Blecker, Th.; Friedrich, G.; Hvam, L./ Edwards, K. ISBN 3-936771-73-1 published by Gito-Verlag, Berlin, 2006.

17. Oddsson, G; Hvam, Lars and Lysgaard, Ole; Conceptualizing Embedded Configuration, conference paper "Customer interaction and Customer Integration" Imcm 22-23 June 2006 Hamburg, Germany, published as part of "Series on Business informatics and Application systems", ISBN 3-936771-73-1, Gito-Verlag, Berlin, 2006.

18. Array configuration - Version 6.2, Modellers guide. Array Technology A/S, www.arraytechnology.com, 2006.

19. Franksen, O.I; Introducing Diakoptical Simulation in Engineering Education. The Matrix and Tensor Quarterly. 1-16, Sep. 1972.

20. Rappa, M; Business Models on the web; www.digitalenterprise.org/models/models.html. Last accessed 21 Jan. 2007. 